\title{
Nephropathy due to Tacrolimus
}

National Cancer Institute

\section{Source}

National Cancer Institute. Nephropathy due to Tacrolimus. NCI Thesaurus. Code C123137.

Kidney damage resulting from tacrolimus. 